CIENCIA Y SOCIEDAD

Volúmen XX, Números 1 y 2

Enero-Marzo 1995

Abril-Junio 1995

REFORMAS POLITICO-INSTITUCIONALES

SINTESIS DE AREAS Y PERSPECTIVAS

FUNDAMENTALES

José Oviedo*

Introducción: ¿Por qué las Reformas?

La imagen de caos institucional y deterioro permanente de las instituciones que existe en la República Dominicana actual evidencia la relación entre la profundización de los problemas económicos y el descenso en la calidad de la vida, y la consistencia o incosistencia de las instituciones. Para muestra, solo algún botón: una baja capacidad institucional de gestión pública se expresa en una baja calidad de los servicios públicos, o el desorden administrativo y normativo de la justicia en la discriminación de los sectores más pobres en las prácticas del sistema judicial (el caso de los desacatos, por ejemplo).

Hay un alerta colectivo en el sentido de que el país puede encaminarse a una crisis de gobernabilidad. La gobernabilidad

*Sociólogo. Director Ejecutivo Grupo Acción por la Democracia. 
se define esquemáticamente como la capacidad del sistema político para canalizar institucionalmente los conflictos y para gobernar con legitimidad y eficacia en la solución de problemas económicos, sociales y políticos.

Esta definición tiene dos dimensiones:

a)Legitimidad Política: capacidad de consenso y consentimiento social con las decisiones legislativas y el establecimiento de reglas y normas.

b) Operatividad: capacidad de ejecución de las reglas de juego.

Para desarrollar mejores condiciones de gobernabilidad es necesario actuar en los dos niveles, abriendo espacios, por un lado, a las relaciones entre gobierno y sociedad civil, y por otro lado, modernizando y profesionalizando las instituciones y el personal del Estado. Esto nos conduce a la temática de los Retos de la Gobernabilidad.

\section{Los Retos de la Gobernabilidad}

A. La nación no podrá tener mejores condiciones de gobernabilidad al margen de agendas y acuerdos entre sus protagonistas partidarios y sociales. Los acuerdos interpartidarios e interinstitucionales son cruciales, así como el rol de la sociedad civil como grupo de presión y participación en la elaboración de agendas nacionales y locales

B. Es necesario desarrollar la capacidad pública para determinar áreas estratégicas de impulso o bloqueo al desarrollo, de conflictos potenciales, y una capacidad de las instituciones y élites gobernantes de prevenir o reducir conflictos por vías institucionales. 
C. A esto debe articularse una capacidad de diseño, decisión y ejecución de proyectos por parte de las instituciones públicas. Estas deben modernizarse y hacerse más representativas paraaumentar su capacidad estratégica y de coordinar y movilizar esfuerzos intergubernamentales y con la sociedad civil.

Lo anterior posee diversos componentes:

1. La elaboración de proyectos de reforma debe conjugar la participación, con la viabilidad técnica y social.

2. Las decisiones han de ser compartidas, y los pactos políticos y sociales han de ser fluidos y transparentes.

3. La ejecución de las reformas deben referirse siempre a voluntades políticas que obedecen a acuerdos en torno a objetivos y metas acordadas, promoviendo la participación, pero también la eficiencia institucional.

4. Vías de evaluación colectiva e institucional, revisión periódica de proyectos.

\section{Criterios de participación y eficiencia}

Los criterios democráticos nos plantean que hay que reforzar vías no tecnocráticas en el proceso de decisión, ejecución y evaluación/participación de la sociedad civil, lo cual requiere rediseñar la estructura y formas de funcionamiento de las instituciones públicas. Lo público, en su sentido original, no es el monopolio total del Estado, sino la esfera en las que interactúan el Estado, las autoridades que representan a la ciudadanía y los representados. Recrear lo público es abrir las instituciones a espacios en que la sociedad civil participe, haciendo más representativas y participativas a las instituciones.

Pero la democratización debe tener coherencia y método. Las diversas políticas públicas, reformas económicas, la 
reforma social y las reformas políticas e institucionales deberían ser concebidas como un "paquete" cuya finalidad es la consolidación democrática y funcional del conjunto del sistema político. La dispersión y/o la arbitrariedad en las reformas crearían una yuxtaposición y riesgo de contradictoriedad y bloqueos mutuos. Las políticas deben retroalimentarse bajo criterios de competitividad sistémica.

"El nuevo escenario nacional debe asumir los retos de interrelacionar y hacer mutuamente consistentes los cambios en el Estado, el sistema político y la economía, con la reforma social, la democratización del poder desde la base y el potenciamiento de los actores locales y comunitarios" (Bolivia: Programa Nacional de Gobernabilidad, 1994). Esto, para mejorar la capacidad de decisión y ejecución de las instituciones democráticas, promoviendo una mayor equidad en la participación y las oportunidades de desarrollo. Impulsar la modernización y democratización del sector público.

La democratización y el logro de mejores condiciones de Gobernabilidad requieren del cambio de las instituciones. Heredamos una tradición caudillista, centralista, clientelista. Las instituciones latinoamericanas, en general, no están preparadas para promover la democracia ni para funcionar bien en un orden democrático. Nuestras democracias parciales requieren de procesos de consolidación institucional.

De ahí, por ejemplo, la importancia del rediseño institucional representado por las Reformas Constitucionales, por ejemplo en Brasil y Colombia. O los cambios legales e institucionales sistemáticos, en Bolivia y en Chile, por ejemplo. 
En la República Dominicana hemos desarrollado algunos elementos de la democracia, como libertad de partidos, elecciones periódicas y libertad de opinión pública, sin consolidadición institucional. Tenemos quizás un régimen político híbrido, con los subsecuentes riesgos de deterioro y crisis incluso en esos mismos elementos (como la crisis electoral de 1994).

El sectarismo de los partidos políticos cortocicuita posibilidades de acuerdos de largo plazo sobre la base de una evaluación de necesidades colectivas a través del diálogo interpartidario y con organizaciones de la sociedad civil.

Mientras se ha puesto atención a las reformas económicas, permanecen las viejas formas de hacer política. El estilo centralista, clientelista, y la corrupción. Los problemas institucionales bloquean el impacto social de las reformas económicas. Por ejemplo, aduanas. La reforma arancelaria plantea en principio el incremento del acceso al consumo para mayorías excluidas. Empero, los escándalos de aduanas develan el asombroso sistema de privilegios, en el que aquellos que tienen más poder y/o más recursos económicos son los que disfrutan de mejores condiciones impositivas. Bloqueo o perversión de la reforma arancelaria como elemento de redistribución del ingreso.

No solo la democracia, sino las propias reformas económicas ameritan de un fortalecimiento institucional. En caso contrario, los problemas institucionales son un cuello de botella para el desarrollo.

Elaboraré a continuación no un listado exhaustivo, sino una síntesis de las que considero son las principales áreas y propuestas de reforma institucional y política no llevadas a cabo en el país, sin incluir las electorales. Hago énfasis en 
varias áreas fundamentales de gobierno y de vinculación entre el aparato gubernamental y la sociedad civil (en sus organizaciones representativas de sectores sociales, territoriales, especializadas, etc.). Hay que resaltar aquí el desbalance entre el impulso de la sociedad civil hacia las reformas y el desgano de los actores partidarios y gubernamentales.

\section{Poder Ejecutivo}

\section{Situación:}

a) Grado de centralización consagrado por el Artículo 55 de la Constitución y ciertamente llevado a la práctica por los gobernantes dominicanos.

b) Centralismo y amplias brechas regionales de desarrollo.

c) Inexistente participación de la ciudadanía en las decisiones de gobiemo y en el diseño o la consulta de políticas públicas.

d) Hipertrofia del aparato estatal, unida a un alto grado de deficiencia en las capacidades administrativa y de gestión pública del Poder Ejecutivo.

\section{Propuestas:}

a) Fortalecimiento de la independencia de los poderes del Estado. Ampliación de las posibilidades de fiscalización del Poder Legislativo (Ejemplo, presupuesto).

b) Reducción de las atribuciones del Poder Ejecutivo en diversos ámbitos.

\section{Poder Legislativo}

\section{Situación:}

a) Dificultades de llegar a acuerdostransparentes y consistentes de cara a la sociedad.

b) Poca fluidez de su función legisladora (letargo o extrema rapidez en la aprobación de proyectos). 
c) Endebles servicios de información, investigación, y apoyo técnico para las decisiones congresionales.

d) Simple antagonismo, o muy limitado ejercicio de su función fiscalizadora o de "chequeo y balance", sobre el Poder Ejecutivo.

e) Superposición de la lógica personalista, clientelista, y sectaria de los partidos políticos a las decisiones congresionales.

f) Precaria representatividad y relativa deslegitimación.

\section{Propuestas:}

a) A nivel electoral: cambio hacia formas territoriales de representación política (como los distritos electorales). Modificación Leyes Electorales. Ley de Creación de Distritos Electorales.

b) Representación sectorial de la sociedad civil en el Congreso.

c) Aumentar las posibilidades de iniciativa legislativa de los grupos ciudadanos.

d) Posibilitar la revocabilidad de los legisladores.

e) Aumento capacidad fiscalizadora del Congreso. Ejemplo: modificación Ley de Gasto Público.

\section{Poder Judicial}

Situación:

a) Extraordinario deterioro institucional: corrupción, endeble infraestructura, pésimas condiciones de administración, violación sistemática de su propia legalidad.

b) Crisis de credibilidad.

c) Extrema politización partidaria del proceso de elección de los legisladores.

d) Debilidad institucional y de procedimientos: preparación, revisión, aprobación, interpretación, aplicación de normas y leyes. 
a) Supresión de la facultad del Senado de elección de los jueces. Mecanismos alternativos de elección y consenso (Asamblea Nacional elige Jueces Suprema Corte, de terna sometida por el Consejo Nacional de la Magistratura, designación por Consejo Nacional de la Magistratura, diferentes formas de composición del Consejo Nacional de la Magistratura. (Ver Brea, 1994:30).

b) Ley de Carrera Judicial.

c) Ley de Administración Presupuestaria del Poder Judicial.

d) Creación de la Fiscalía General de la Nación.

\section{Nivel Municipal}

\section{Situación:}

a) Extrema dependencia del Gobierno Central.

b) Escasa capacidad de gestión de los Gobiernos Locales.

c) Ausencia de los Ayuntamientos de la formulación de políticas públicas.

d) Muy limitada participación de las organizaciones de base.

\section{Propuestas:}

a) Descentralización (de los recursos y de las decisiones).

b) Ampliación de la participación local y definición de metas territoriales para las políticas públicas. Complementar la representación política con la representación de sectores sociales y territoriales. Promover el fortalecimiento y democratización de las organizaciones de la sociedad civil.

c) Capacitación y mejoramiento de la gestión operativa.

d) Modificaciones Constitucionales ampliando las atribuciones de los Ayuntamientos y limitando las 
atribuciones del Poder Ejecutivo

e) Ley de Descentralización.

f) Ley de Participación.

g) Ley de Creación de Consejos Consultivos Municipales.

h) Ley de Plebiscitos Municipales.

\section{Reforma de la Constitución}

\section{Situación:}

a) Obsolescencia texto Constitucional. Carácter no democrático, centralismo presidencialista.

\section{Propuestas:}

a) Disminución Poderes del Ejecutivo (Ejemplo: Artículo 55, modificar poder autorización a los Ayuntamientos, nombramiento arbitario de funcionarios públicos, modalidades de ejecución presupuestaria).

b) Separación Poderes del Estado.

c) Fortalecimiento del Poder Judicial.

d) Consenso en torno a la necesidad de Reformas. ¿Cómo reformarla? Casos de Brasil y Colombia. O reformas desde arriba y por razones coyunturales? Mecanismos institucionales: Asamblea Constituyente por elección popular. Modificación Títulos Reforma Constitucional actual Constitución.

\section{Criterios Finales}

1. Es necesario un proceso de articulación, dada la dispersión de las diversas propuestas. Estrategia global que produzca un mejoramiento de las capacidades del sistema político. Ejemplo: el plan de modernización y fortalecimiento del Estado (1992) en Bolivia.

2. Participación de diversos actores sociales, regionales, ygubernamentales. Concertación y acuerdos mínimos. 